\title{
La protección legal de la creatividad del docente
}

DOI: $10.46932 / \operatorname{sfjdv2n2-170~}$

Received in: March 1st, 2021

Accepted in: May 30th, 2021

\author{
Cristina Cázares Sánchez \\ Doctorado en Derecho, UNAM \\ Current Institution: Facultad de Derecho UNAM
}

Full address (can be institutional or personal, as you prefer) Av. Universidad 2219, Col. Copilco,

Delegación Coyoacán, C.P. 04510, Ciudad de México

E-mail.ccazaress@derecho.unam.mx

\section{RESUMEN}

El uso de tecnologías de información y comunicación aplicadas al aula es una constante en la educación actual. Se reconocen y se fomenta las competencias digitales dentro del trabajo docente, y es el docente el encargado de incluir dentro de la planeación de clase estas herramientas mediante las secuencias didácticas. La forma, el diseño de estas secuencias didácticas deviene de la creatividad del profesor, el trabajo creativo que está protegido legalmente, así como la imagen y demás materiales realizados por el docente para y dentro del aula.

Dentro del aula se conforma un ambiente de confianza e intimidad entre docente y alumno que confunde los límites acerca de la divulgación del material realizado por el docente para el uso en clase habiendo fugas de material que puede ser plagiado y usado por otros docentes.

Tal vez, sea necesario redefinir los límites de protección y divulgación del trabajo creativo del docente.

Palabras clave: Derechos de autor, creatividad docente, derecho de privacidad

\section{INTRODUCCIÓN}

La tarea docente implica una constante capacitación, esfuerzo de horas curso adicionales a las horas clase institucionales. Requiere del docente el desarrollo y fomento de conocimientos como saber hacer, saber ser y saber estar, en su propia disciplina y en el uso o aplicación de las tecnologías de información y capacitación. Sin embargo, lo más importante, es el desarrollo a través de las experiencias vividas, a través de la observación de las dinámicas de un grupo tras grupo, donde el aprendizaje y la creatividad del docente se activan.

La creatividad del docente es inherente al mismo, el diseño, el producto de su trabajo debe estar legalmente protegido ante el plagio. El propio docente-autor debe reconocerse como tal y fijar los límites de la divulgación de sus materiales.

Esta ponencia tiene como objeto reflexionar sobre esta vulnerabilidad que presentan los docentes creativos ante el plagio de los diseños de sus secuencias didácticas. 


\section{DESARROLLO}

\subsection{OBJETIVO:}

El uso de las Tecnologías de Información y Comunicación aplicadas al Aula se ha convertido en un eje transversal de la educación en general y la Educación Superior, no está exenta. Se reconoce que el docente debe capacitarse constantemente para mejorar en la aplicación de estas tecnologías de forma eficiente y también, en las estrategias didácticas para diseñar secuencias didácticas que resulten de aprendizajes significativos. Así también, el docente debe conocer las teorías de evaluación. Con todo ello, autoevalúa la pertinencia de los diseños realizados para ejecutarlos en clase.

En lo anterior, es vital la existencia de un elemento subjetivo del profesor: la creatividad. De hecho, se considera como un desafío para la educación del siglo XXI (Klimenko, 2008).

La creatividad pareciese ha pasado de una cualidad a una competencia del profesor, forzosamente debe desarrollarla, ejercerla, acrecentarla para lograr diseños complejos de secuencias didácticas innovadoras y originales que utilizará en las clases, ocupando 5 o más horas en su diseño y aun cuando su aplicación es de 1 hora. Además de exigirle al profesor esta competencia, la debe fomentar en sus alumnos.

Diseñar, ejecutar, innovar, aplicar métodos novedosos de evaluación en clase, es sin dudas una actividad creativa un acto creativo con implicaciones legales de protección que pocas veces se observan dentro de la práctica docente.

¿Es el ámbito educativo de esencia socialmente colaborativa, respetuosa y de finalidad cultural un ámbito donde sea innecesario la protección legal del trabajo creativo del docente dentro de aula y más allá acerca de la protección de su privacidad del docente y alumno?

Pareciese que, el fin de la educación vista como una función social, es suficiente para diluir la autoría y esfuerzo del docente dejando el trabajo creativo a un mundo abierto, donde se permita compartir el diseño a otros pares.

¿Acaso se considera al aula un espacio libre donde es irrelevante si el alumno sin mediar palabra obtiene una foto de un esquema elaborado por el profesor en el pizarrón a partir de la creatividad? ¿Cómo docentes trabajamos en un ámbito social superior que implica tácitamente el compartir conocimiento incluyendo la creatividad del docente?

\section{MARCO DE REFERENCIA:}

\subsection{CREATIVIDAD}

SI la actividad de diseño de las estrategias didácticas es un acto creativo, definir y distinguir los elementos de creatividad es esencial, Klimenko (2008) establece: 
En primer lugar es importante resaltar que existen dos maneras de concebir la creatividad: como una H-creatividad o creatividad al nivel social, entendida como una contribución a los campos simbólicos de la cultura, y una P-creatividad o creatividad a nivel personal, como un logro personal en cualquier ámbito del desempeño ${ }^{1}$ (Klimenko 2008:195)

La definición anterior permite observar que es parte de la tarea del docente como función social de la educación contribuir a los campos simbólicos de la cultura de sus alumnos, sin embargo, esto no implica una renuncia a la autoría, ni un anonimato del esfuerzo de la estructura mental del docente. Respecto al segundo concepto, se entiende que el docente siempre debe actuar con creatividad, aunque un docente puede ser más creativo que otro por razones de capacidad psicológica o metacognitivas (Perkins cit por Boden, 1994).

A su vez, el docente, el tipo de creatividad a considerar para realizar el diseño de las secuencias didácticas, es la P-Creatividad de alumno, la creatividad a nivel personal. Esta tarea exige del docente un nivel mayor de P-creatividad propia porque debe idear y aplicar un diseño general reconociendo como lo señala Boden (1994) que algunos alumnos de su clase serán más creativos que otros:

...Albertina Mitjans afirma que 'la creatividad tiene en su base una configuración compleja de recursos personológicos cuya formación y expresión dependen de las múltiples y complejas interacciones del sujeto en los distintos sistemas actividades-comunicación donde ha transcurrido

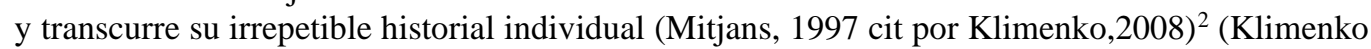
2008:203)

La competencia creativa del docente es de dos sentidos, desarrollar la propia y desarrollar la del estudiante a la cual se dirigen las secuencias didácticas.

Una manera de detonar el desarrollo de creatividad, es el momento de enfrentarse a problemas y buscar la solución, el docente, es en sí creativo por necesidad, cuando está frente a grupo soluciona los problemas de clase, evaluación, institucionales e incluso de infraestructura, sin embargo, la creatividad como competencia docente va más allá de la solución de problemas cotidianos propios del desempeño del trabajo docente, sino el reto es detonar, también la creatividad en el estudiante para lograr una búsqueda cognoscitiva:

La realización exitosa de la actividad de la búsqueda cognoscitiva por parte de los alumnos está condicionada por un correcto planteamiento del orden científico, lógico y pedagógico de los elementos problemáticos y por la motivación de los estudiantes hacia la ejecución de acciones teóricas y prácticas encaminadas a darles respuesta. Dicho de otra forma, depende del modo en que el contenido se problematiza ${ }^{3}$ (Nuñez 2003:5)

\footnotetext{
${ }^{1}$ Klimenko, Olena. (2008) "La creatividad como un desafío para la educación del siglo XXI. Educación y Educadores". Universidad de la Sabana, Cundinamarca, Colombia, vol 11, núm. 2, diciembre. Pp. 191-210. P. 195

2 Ibidem. P. 203

${ }^{3}$ Núñez-Malherbe, R. (2003) “La enseñanza problémica. Una estrategia didáctica coherente”. En Renglones, Revista del ITESO, núm.54: El laberinto de las matemáticas. Tlaquepaque, Jalisco: ITESO. P.15
} 
Y el autor del adecuado planteamiento del problema, no es otro que el docente. En pocas palabras, el éxito de una actividad diseñada como secuencia didáctica de aplicación en el aula, que lleva al docente de una actividad mental de horas, depende la existencia y desarrollo de la P-Creatividad o creatividad personal.

El contenido de la creatividad docente a considerar para el diseño de las secuencias didácticas implica según Menchen- Bellón (1998) citado por Iglesias (2014):

1. Humor

2. Juego

3. Relajación

4. Trabajo en equipo

5. Analogías

6. Audición Creativa

7. Búsqueda

8. Discrepancias

9. Escritura creativa

10. Lectura creativa

11. Paradojas

12. Interdisciplinariedad

13. Preguntas provocadoras

14. Tolerancia

15. Visualización ${ }^{4}$ (Menchén-Bellón 1988:349-362)

La creatividad como competencia propia del docente y como competencia a desarrollar en el alumno, es tal vez el reto primordial en la educación, marca el comienzo y éxito de una estrategia de aprendizaje. La creatividad innovadora es el detonador de la motivación del detonante de la curiosidad del alumno.

Un esfuerzo de actividad mental del docente suficientemente complejo para ser protegido y reconocido por la estructura legal.

Es decir, que el resultado contenido en el diseño y aplicación de las secuencias didácticas de cada docente son de resultado personal, atañen a la creatividad y conocimiento de ese docente y no de otro.

\footnotetext{
${ }^{4}$ Menchén-Bellón (1998) citado por Iglesias Casal, Isabel (2014) "Creatividad, emociones y motivación: el modelo CEM en la construcción de la ecología del aula” en La enseñanza del Español como LE/L2 en el siglo XXI. Narciso Miguel Contreras Izquierdo (ed. Lit) pp. 349 a 362. P. 351 y 352.
} 
La creatividad como competencia se desarrolla con la capacitación, con el uso, con la práctica, incluyendo el uso de tecnologías de información y comunicación. Con las vivencias y experiencias de cada docente.

\subsection{INTIMIDAD Y AULA.}

El docente para detonar esa creatividad de sus alumnos los debe observar conocer los rasgos de personalidad de los sujetos-alumnos y a su vez, esta observación es recíproca. La motivación del alumnado también depende de la cercanía del docente que se deriva de espacios y tiempos compartidos, de la interacción misma según Escobar Medina (2015):

...Lo cierto es que la interacción alumno-docente se ve permeada de más elementos, de una convivencia que tiene como principios básicos el respecto (sic), la confianza y la aceptación por parte de ambos, es decir de una relación cálida, afable que permita la atracción y proximidad con el saber, con el conocimiento. ${ }^{5}$ (Escobar 2015:s/p)

En nuestro afán por ocultar las áreas que el docente considera privada, sus actos e imágenes dentro del aula, abren interpretaciones de esas ventajas al estilo de Fritzen (1982) que construyen actividades tramposas de comportamiento (Fritzen, 1982:14), originando reacciones en el otro como es desconfianza, retraimiento, en pocas palabras desmotivación, precisamente un efecto contrario.

Ahora ¿Qué tanta información damos y cómo nos protegemos? Indudablemente, cualquiera que haya estado frente a grupo, nota las miradas, como docentes, sabemos que los sobrenombres con los cuales nos identifican los alumnos atañen a la imagen o información que el docente da de si mismo incluso sin desearlo. Si deseamos no dar información alguna acerca de nosotros mismos frente a un grupo, el rol del docente será un observador mudo, donde no se recibe ninguna retroalimentación ni surge interacción alguna, Fritzen lo llamó: el Tortuga por su caparazón. (Fritzen: 1982:17)

Resulta cierto que el docente y los alumnos intercambian información personal:

1. Voluntaria

2. Involuntaria, con la imagen, las interpretaciones de las actitudes y del comportamiento dentro de clase, con las opiniones o incluso con las posturas ideológicas respecto a los temas de clase.

Si es así, si los docentes y los alumnos manifiestas posturas ideológicas, de creencias, incluso de preferencias sexuales, de gustos de consumo, de entorno familiar, como de imagen, cuando se incorporan las tecnologías de información y comunicación al Aula ¿Algo tan cotidiano como capturar una foto de la

\footnotetext{
${ }^{5}$ Escobar Medina, M (2015) Influencia de la interacción alumno-docente en el proceso de enseñanza-aprendizaje. PAAKAT: Revista de Tecnología y Sociedad, Vol $0 \quad$ núm $8 . \quad$ Recuperado de http://www.udgvirtual.udg.mx/paakat/index.php/paakat/article/view/230/347As
} 
información en el pizarrón donde también sale la imagen del docente, debe contener un aviso de privacidad? Bajo lo cual el consentimiento de las partes involucradas (docente y alumno) en el tratamiento de datos personales es esencial.

Al utilizar las tecnologías de la información y la comunicación en el aula como parte del diseño de una secuencia didáctica, lo que está generando es un intercambio de información: el uso de plataformas educativas virtuales, redes sociales, la nube: Google Drive, Dropbox, etc. A través de las cuales se pone a disposición del alumno el diseño, instrucciones, rúbricas, guiones, lineamientos y hasta ejemplos tomados de cursos pasados. Esto es, se abre una ventana de información de libre acceso para el alumno al trabajo de origen creativo y originalidad del profesor. Donde no se pone límite expreso al uso de esta información. Así puede compartirlo libremente con miembros de la clase, pero también con otros compañeros e incluso con otros profesores.

Esta información de datos deliberadamente y de forma voluntaria compartida forman parte del Derecho de privacidad originado en la interacción docente-alumno. De la misma manera que en el derecho laboral, los trabajadores tienen la obligación de resguardar la información que por motivo de su trabajo conozcan (Código Penal federal 2018: artículo 210) ¿también en los alumnos cabría esa obligación? ¿las secuencias didácticas conforman información esencial y reservada derivada de la creatividad del docente que hacen que su clase sea como lo es, en atención a componentes subjetivos?

La profesión docente conlleva el compartir conocimientos, una labor social es tal vez que por esta razón, se entienda que el trabajo del docente en aula, aún en su estrato más profundo, el diseño y material novedoso y original producto de la P-creatividad del docente y no de otro, se comprenda dentro de este material de libre acceso y además, con la ficción del como si se diese el consentimiento para que otros docentes y alumnos, fuera de esa interacción dada en el aula, lo pudiesen utilizar, sin que medie consentimiento alguno del autor. ¿Acaso el ser- docente borra el ser-autor?

\subsection{LOS DERECHOS DE AUTOR Y LA PROTECCIÓN DE DATOS PERSONALES}

Legalmente la protección de la creatividad para realizar una obra original y novedosa se encuentra en el artículo 28 Constitucional en el párrafo 10:

Tampoco constituyen monopolios los privilegios que por determinado tiempo se concedan a los autores y artistas para la producción de sus obras... (Constitución Política de los Estados Unidos Mexicanos: Artículo 28: Párrafo 10)

La ley federal del Derecho de Autor (última reforma DOF:15-06-2018) tiene por objeto la protección de los autores de un listado de obras establecidos en el artículo 13 de la misma ley, aunque exactamente no incluye al trabajo académico, en el último párrafo establece: 
...Las demás obras que por analogía puedan considerarse obras literarias o artísticas se incluirán en la rama que les sea más afín a su naturaleza. (Ley Federal de Derecho de Autor, artículo 13: último párrafo)

Así los diseños, las secuencias didácticas que elabora el docente utilizando su P-Creatividad, si son objeto de protección legal dentro de los Derechos de autor, dando los siguientes derechos morales según el artículo 21 de la ley citada:

1. Divulgar la obra o mantenerla inédita. En el caso de las secuencias didácticas siempre se da a conocer al alumno

2. Exigir el reconocimiento de su calidad de autor respecto de la obra por él creada y la de disponer que su divulgación se efectúe como obra anónima o seudónima. En el caso del trabajo docente no hay obra anónima ni seudónima, así se divulga al grupo como resultado del trabajo creativo del docente.

3. Exigir respeto a la obra, oponiéndose a cualquier deformación, mutilación u otra modificación de ella, así como toda acción o atentado a la misma que cause demérito de ella o perjuicio a la reputación de su autor. En el trabajo creativo del docente, puede claramente informar a sus alumnos que solo es de uso para el grupo, no se puede compartir y mucho menos debe servir de base o modificación para otros docentes.

4. Modificar su obra.

5. Retirar su obra del comercio. Aquí se entiende que el trabajo creativo del docente es de fin social.

6. Oponerse a que se le atribuya al autor una obra que no es de su creación. (Ley Federal de Derecho de Autor, articulo 21)

Es decir, que los docentes tienen el derecho moral sobre las secuencias didácticas diseñadas como productos de su P-Creatividad, así como los alumnos de los productos obtenidos como resultados de estas. Es aquí cuando, existe un dilema si el profesor forzosamente debe incluir un aviso a los alumnos para mostrar los productos sobresalientes obtenidos como evidencia de su trabajo docente en congresos, artículos, reuniones y eventos de carácter académico. Así como el docente, tiene el derecho exclusivo de limitar la divulgación de los diseños de la secuencia didáctica o bien del material incluyendo las fotos capturadas a los apuntes del pizarrón, la grabación de las clases, ponencias e incluso el uso de imagen.

Respecto a los medios tecnológicos existen la protección del derecho de autor a través de los denominados creative commons (www.creativecommons.org) que permiten compartir el trabajo a través de plataformas digitales o medios digitales dando la elección de compartir completamente el trabajo creativo o restringir las obras que se deriven.

Queda asentado que el trabajo creativo desarrollado por el docente en las secuencias didácticas, que incluyen la elección de herramientas tecnológicas aplicadas al aula para obtener las evidencias (no así 
los productos) es materia de protección legal de derechos de autor del docente y no puede ser reproducida ni compartida sin el previo consentimiento. Es decir, que el docente libremente puede limitar las fotografías dentro de clase, establecer que las plataformas o herramientas digitales donde comparte la información con sus alumnos, es solo para sus alumnos y no para otros grupos ni mucho menos otros docentes.

Por su parte, en los productos, incluyendo los videos o audios donde aparezca la imagen o voz de los alumnos, les pertenece autoralmente a los alumnos, por ello, se requiere su previa autorización al momento de compartirlos en congresos, artículos, ponencias, entre otros actos académicos donde participa el docente.

\subsection{PROPUESTA DE CÓDIGO DE ÉTICA, INTERPARES, RECONOCIMIENTO A LA} CREATIVIDAD, DERECHO AL CONSENTIMIENTO, MODIFICACIÓN Y OBRA DERIVADA DEL MISMO PROFESOR.

Por último, no basta con la protección legal, sino con un compromiso ético entre profesor y alumno e incluso entre profesor-profesor. Se requiere la elaboración de códigos de ética, no solo institucionales, sino interpares para evitar el plagio de las secuencias didácticas que necesariamente se comparten a los alumnos, debido a la divulgación indirecta de alumno-profesor, a otros docentes y que se utilicen de base para elaborar sus secuencias didácticas o incluso se apliquen sin modificación alguna, solo de contenido temático.

\section{CONCLUSIONES}

El trabajo docente del diseño instruccional incluyendo como resultado las secuencias didácticas aplicadas a clase, así como la elección y forma de aplicación de la tecnología de información y comunicación seleccionada son actos creativos del docente y pertenecen a su obra. Libremente puede limitar la divulgación del material realizado para estas secuencias didácticas como apuntes, manuales, tutoriales (elaborados por el propio docente).

Los productos de las secuencias o evidencias pertenecen al derecho de autor del alumno o alumnos, así se requiere un previo aviso y consentimiento de los mismos para divulgarlos por parte del docente.

Los docentes debemos actuar con responsabilidad ética, no solo en el uso adecuado de las tecnologías de información y comunicación aplicadas al aula, sino también con el creativo debido respeto del trabajo de los otros docentes. Volvamos a la cortesía de pedir permiso. 


\section{REFERENCIAS BIBLIOGRÁFICAS}

Bibliografía.

Boden, Margaret (1994) La mente creativa mitos y mecanismos. Barcelona: Editorial Gedisa Creative Commons PO Box 1866, Mountain View, CA.94042

Escobar Medina, M (2015) Influencia de la interacción alumno-docente en el proceso de enseñanzaaprendizaje. PAAKAT: Revista de Tecnología y Sociedad, Vol 0 núm 8 . Recuperado de http://www.udgvirtual.udg.mx/paakat/index.php/paakat/article/view/230/347As

Fritzen, Silvino José (1982) "La ventaja de Johari” Ejercicios de dinámica de grupo, de relaciones humanas y de sensibilización. Trad Tedoro E. Batlle (1987). 5ª edición. España.

Klimenko, Olena. (2008) "La creatividad como un desafío para la educación del siglo XXI. Educación y Educadores”. Universidad de la Sabana, Cundinamarca, Colombia, vol 11, núm. 2, diciembre. Pp. 191 210

Menchén-Bellón (1998) citado por Iglesias Casal, Isabel (2014) "Creatividad, emociones y motivación: el modelo CEM en la construcción de la ecología del aula” en La enseñanza del español como LE/L2 en el siglo XXI. Narciso Miguel Contreras Izquierdo (ed. Lit) pp. 349 a 362

Núñez-Malherbe, R. (2003) "La enseñanza problémica. Una estrategia didáctica coherente”. En Renglones, Revista del ITESO, núm.54: El laberinto de las matemáticas. Tlaquepaque, Jalisco: ITESO

Legislación

Cámara de Diputados (2006) Constitución Política de los Estados Unidos Mexicanos (última reforma DOF 12-04-1917) recuperada de www.diputados.gob.mx

Cámara de Diputados (2006) Código Penal Federal (última reforma DOF 12-04-2019) recuperado de www.diputados.gob.mx

Cámara de Diputados (2006) Ley Federal de Derechos de Autor (última reforma DOF:15-06-2018) recuperado de www.diputados.gob.mx 